\title{
Understanding Solid Waste Management Practices in Developing Countries: From Waste Disposal to Recovery of Resources
}

\author{
Foday Pinka Sankoh \\ Department of Science Education, Ernest Bai Koroma University of Science and Technology, Port Loko, Sierra Leone
}

Email address:

fpsankoh@ebkust.edu.sl,fodaypinka_sankoh@yahoo.com

To cite this article:

Foday Pinka Sankoh. Understanding Solid Waste Management Practices in Developing Countries: From Waste Disposal to Recovery of Resources. American Journal of Environmental Protection. Vol. 9, No. 3, 2020, pp. 39-43. doi: 10.11648/j.ajep.20200903.11

Received: July 8, 2019; Accepted: August 6, 2019; Published: May 28, 2020

\begin{abstract}
This paper sought to compare the three methods of waste management in developing countries and identify the most economical option. Structured questionnaires were administered to three city councils in Sierra Leone with respect to landfills, composting and incineration as waste disposal methods. On-the-sport observation and personal interviews were also used to collect some useful data. The data was analyzed by using SPSS packages. The results showed that Landfills are the most common way of disposal in developing countries but they have not been successful in countries like Sierra Leone due to limited time frame of usage. Composting eliminates methane production, and increase life expectancy of landfills. Incineration does not necessarily replace landfilling but it significantly reduces the necessary volume of disposal. The study concludes that none of these three methods is free from problems. Therefore the study recommends that developing countries should adopt resource recovery, the most economical and best possible option to reduce the waste disposal problem keeping in mind the cost effects on the respective governments.
\end{abstract}

Keywords: Sierra Leone, Solid Waste Management Practices, Waste Disposal, Recovery of Resources

\section{Introduction}

The waste management situations in most developing countries show that the goals and principles of waste management are far from being achieved Pacione [1]. While data is generally lacking in the waste sector of developing countries, available studies on the topic suggest that solid waste management in generally characterized by inefficient collection methods, insufficient coverage of the collection systems and improper disposal of municipal waste $(1,2)$. Major urban settlements are therefore, characteized by waste accumulations and poor environmental sanitation $[1,2]$. In 2002, the United Nations Centre for Human Settlement (UNHabitat) raised concern about the solid waste situation in poor country cities. The need for the collection and disposal of solid waste in urban settlements is far from adequately recognized. Uncollected refuse accumulates in drains, roads and open spaces, disrupting community life and creating additional problems in the operation of other public Service [3]. In many Third World cities, writers suggest that large proportions (between 30 and 50 percent) of the solid waste generated by the residents are never collected for disposal and end up rotting on the streets, in drains and in streams [1, 2]. For instance, the study [2] has reported the extensive lack of solid waste collection in cities across the developing world. The paper [1] has also commented on the lack of provision for urban waste management in poor countries and the resulting poor environmental conditions in the cities. According to him, most poor city governments have great difficulty regarding the collection and safe disposal of solid wastes. He estimated that between one third and one half of all solid waste generated in Third World cities(examples Freetown, Port Harcourt, Nairobi, Kampala, Dakar etc.) remains uncollected and the collection rate could be as low as 10-20 percent in some cases. Depicting a similar picture of the problem, the research [4] has estimated that in some cases, up to 60 percent of solid waste generated within urban centres in poor countries remains uncollected and such refuse accumulates on waste lands and streets, sometimes to the point of blocking roads. 
The waste accumulation problem is not only limited to African cities. Asian and Latin American cities equally face daunting solid waste problems and many are unable to provide adequate waste disposal services for their residents. In 2007, a study of the urban solid waste situation in the eleven countries eleven countries that form the Asian Productivity Organization showed that solid waste management is a major challenge in Asian cities. However, this is not to say that Latin American cities have no problems with waste disposal. Waste accumulation is one of the biggest environmental concerns in Latin American cities is a key contributor to the urban environmental crisis that many Latin American cities face. Despite several programs and studies about the problem and potential solutions such as recycling, the concern remains.

The studies [2, 5] also reported abysmal waste situations in a number of Latin American cities including Bogota (Columbia), where some 2,500 tonnes of solid waste is left uncollected every day and is simply left to rot in small tips or in canals, sewers and streets; and Sao Paolo (Brazil) where one-third of the population is living in areas without any service to collect solid waste. Furthermore, 10 per cent of waste collected in the municipality of Sao Paolo is said to be improperly discarded in terms of both the treatment process and the location of waste dumping areas.

The problem of waste management and disposal is very acute in Sierra Leone since more than $90 \%$ of waste is currently disposed of by open dumping. Some commonly used methods by which the waste could be managed are: landfilling, composting and incineration. However, these methods are inefficient and pose environmental and health hazards. This paper argues that the solution to waste management is not merely technical, but also organizational. There is a great need to move away from the disposal-centric approach and toward the recoverycentric approach of waste management. This shift requires some level of stakeholders' participation through regulating and monitoring of solid waste generation and disposal.

\section{Materials and Methods}

The study was conducted in three (3) different city councils in Sierra Leone, namely: Freetown city council, Bo city council and Makeni city council. The method involved the administration of structured questionnaires to one hundred and twenty (120) respondents in these city councils. The questionnaire sought to obtain data on the most economical method of waste disposal in developing countries. The questionnaire focused on the different methods used to dispose waste considering the cost effectiveness of each method on the government. The data for this study was collected from both primary and secondary sources to present the findings on understanding solid waste management practices and the cost effect on the government. Firstly, desk study of secondary data wherein documents and records relating to appropriate data sources including books, journals, newspapers, and activities both published and unpublished were studied to obtain background information on the disposal of solid waste in developing countries. Secondly, visitations to the different city councils were made in order to interview stakeholders in waste management practices at random. The questions designed were tailored to derive information on understanding solid waste management practices in developing countries. Information obtained was used to update the data collected during the desk study. Most of the questions were closedended. Out of the one hundred and twenty (120) questionnaires administered one hundred (100) were received given $83.3 \%$ response. $83.3 \%$ sample size was the representative population which was easy to manage and came up with good results. SSPS software was used to present and analyse the data.

\section{Results and Discussion}

\subsection{Landfilling}

Figure 1 shows a bar chart on data obtained from respondents on the different landfills used to dispose solid waste in their respective councils.

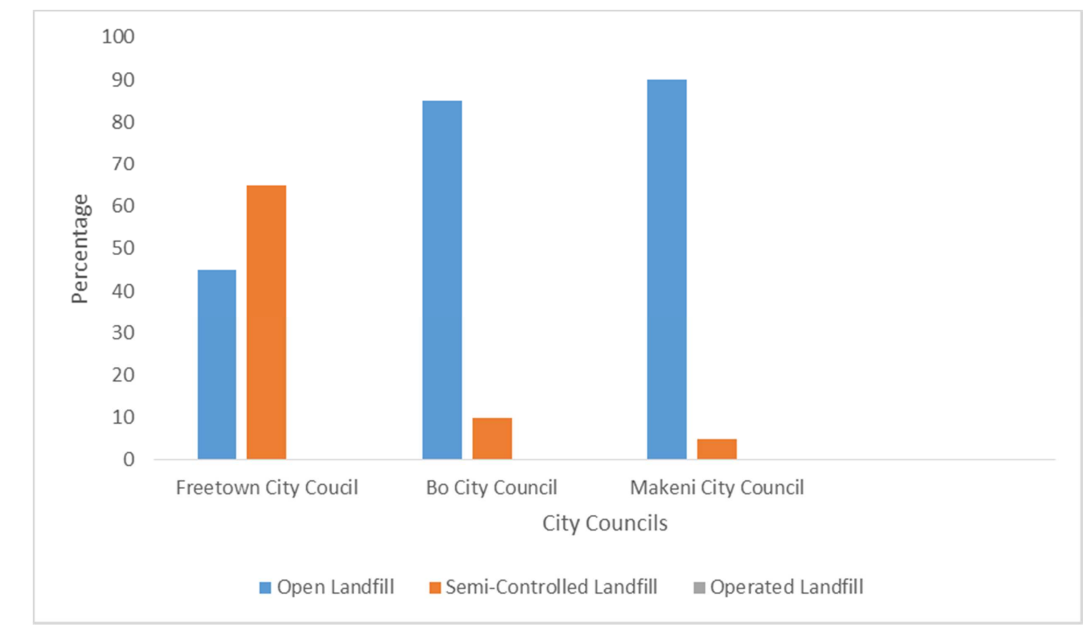

Figure 1. A bar chart showing different landfills. 
The Figure 1 above revealed that open landfilling is the commonest form of waste disposal in the cities of Sierra Leone. A landfill is an engineered design consisting of a variety of systems for controlling the impact of land disposal on human health and safety and on the environment, particularly the ground water. Landfills can be classified into three categories, which are: open dumps or open landfill(the most common in all developing countries, involve the refuse simply being dumped haphazardly into low lying areas of open land, Semi-controlled or operated landfill (designated sites where the dumped refuse is compacted and a topsoil cover is provided daily to prevent nuisances and sanitary landfills (used in developed countries and have facilities for interception and treatment of the leachate using a series of ponds). Landfills are the most common way of waste disposal in the cities of developing countries [6]. Generally they are found within and at the outskirts of the urban city areas, turning into sources of contamination due to the incubation and proliferation of flies, mosquitoes and rodents. The siting of landfills has proved to be a problem to nearby residents in most developing cities of the world [7], Freetown is no exception.

Landfills which are not properly planned and managed are known for their smelly and unsightly conditions [8]. These conditions are worse in the summer because of extreme temperatures, which speed up the rate of bacterial action on biodegradable organic material [9]. Normally, it is the wet waste that decomposes and releases a bad odour. The bad odour affects the people settled next to the dumpsite, which clearly shows that dumpsites have serious effects to the people settled around or next to them [7]. The studies stated that pollution is not directly transferred from land to people, except in the case of dusts and direct contact with toxic materials. $[7,10]$

Pollutants deposited on land usually enter the human body through the medium of contaminated crops, animals, food products, or water [10]. Land pollution can also damage terrestrial ecosystems, resulting in the deterioration of the conservation on and amenity value of the environment [9].

\subsection{Composting}

Composting is the process of aerobic biological decomposition of organic materials under controlled condition of temperature, humidity and $\mathrm{PH}$ resulting in nutrient-rich humus. The word 'compost' is derived from the Latin verb 'componere', which means to put together.

Composting involves the putting together of a mixture of vegetable residue, animal matter, soil and water to form humus. The amount of compostable material in the waste of developing countries is $80-85 \%$. The typical composition of municipal solid waste in Sierra Leone is given in Table 1.

Table 1. Composition of solid waste in Sierra Leone.

\begin{tabular}{llll}
\hline Solid waste & Freetown city (Av. Wt.) \% of Total & Makeni city (Av. Wt.) \% of Total & Bo city (Av. Wt.) \% of Total \\
\hline Garbage & $83.5(69.1)$ & $72.9(62.3)$ & $100.5(77.6)$ \\
Plastic & $9.1(7.6)$ & $11(9.4)$ & $6.7(5.2)$ \\
Metal & $3.4(2.8)$ & $4.1(3.5)$ & $4.0(3.1)$ \\
Glass & $3.6(3.0)$ & $3.4(2.9)$ & $3.8(2.9)$ \\
Paper \& Cardboard & $11.0(9.1)$ & $14.3(12.2)$ & $6.4(4.9)$ \\
Ash & $3.7(3.1)$ & - & - \\
Others & $6.5(5.3)$ & $11.4(9.7)$ & $8.2(6.3)$ \\
\hline
\end{tabular}

The waste composition of developing countries makes it clear that windrow composting, which is the least expensive and most appropriate to the socio-economic and climatic conditions is the best possible option to deal with municipal solid waste. However, it must be stated that composting helps to solve some important problems. In fact through composting, the methane production is eliminated which helps to achieve the requirements of European Directive L999/31/EC concerning landfills and reduction targets for the generation of those gases contributing to the greenhouse effect. It also allows recovery of recyclable materials and the life expectancy of landfills increased. Composting is considered by many to be an ideal solution to many of the solid waste disposal problems since it produces a saleable product. Composting has a long tradition in many developing countries [11] and is particularly wide spread in the rural areas. There is no centralized large scale composting plant established in the rural areas. More importantly, studies have determined that composting is difficult because the waste arrives in a mixed form and contains a lot of non-organic material.
When mixed waste is composted, the end product is of poor quality. The presence of plastic materials in the waste stream is especially problematic, since these materials do not get recycled or have a secondary market. In the absence of segregation, even the best waste management system or plant will be rendered useless. This raises a fundamental question: Who is responsible for the waste produce? If the polluter pays principle is adopted in developing countries, then whoever generates the waste has to take the majority of the responsibility for cleaning it up. In the context of mixed waste, the households, industries and establishments that generate the waste have to take the first responsibility for segregating the waste. Once segregated, the biodegradable items could be composted and the rest of the material could be recycled. Thus, participation of all stakeholders is necessary to the resource recovery approach to waste management. This participation would naturally lead to the decentralized approach with the following advantages:

i. Primary waste collection improves and the residents become less dependent on the collection of municipal waste. 
ii. It can be implemented with reduced investment and low operating costs.

iii. Manual composting is easily integrated into the prevailing Indian socio-economic conditions, as it is labour intensive and offers employment opportunities.

iv. The compost can be sold to the farmers. With high quality compost, there would be a ready market.

\subsection{Incineration}

Figure 2 shows a bar chart on data obtained from respondents on the use of incinerators to dispose solid waste in their respective councils.

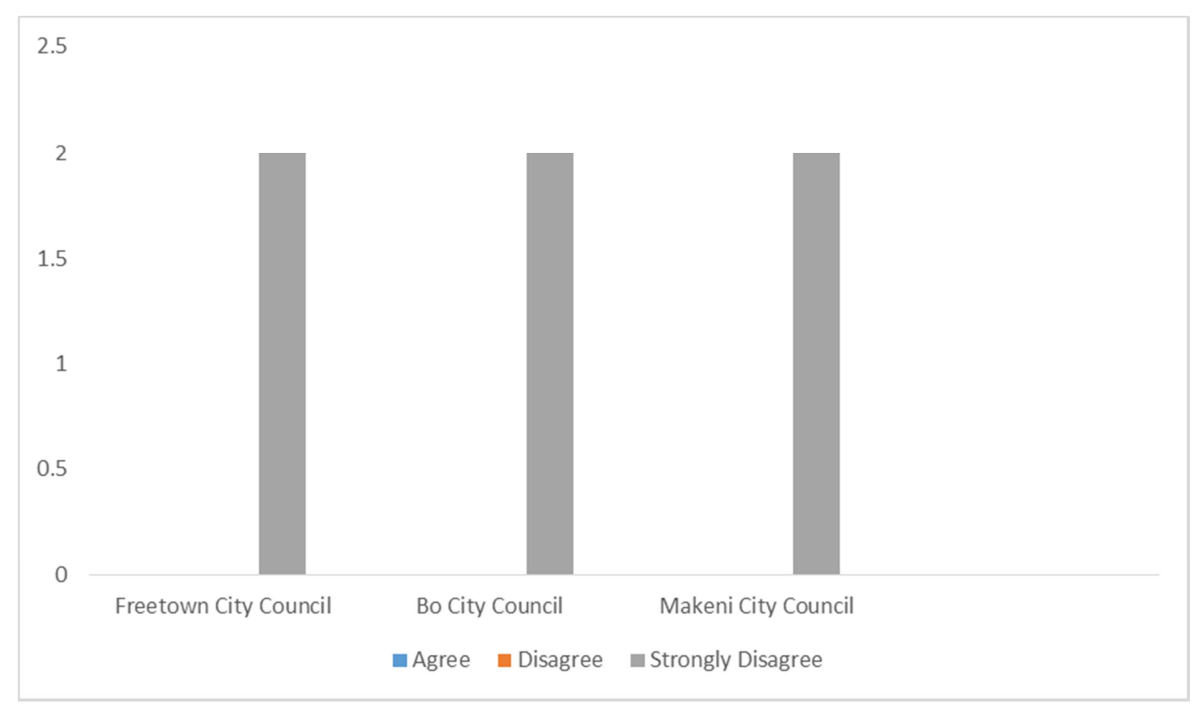

Figure 2. A bar chart showing respondents views on the use of incinerators.

The Figure 2 shows that all the respondents strongly disagreed on the use of incinerators to dispose solid waste.

Incineration refers to a waste treatment process that involves the combustion of organic substances contained in waste materials. Incineration of waste materials converts the waste into ash, flue gas and heat. The ash is mostly formed by the inorganic constituents of the waste, and may take the form of lumps or particulates carried by the flue gas. Since physical matter cannot be destroyed, an incinerator actually transforms the original waste materials into several new forms (ash, flue gas and heat), which are far more difficult to deal with than the original raw waste materials.

\subsection{A. Good Option}

Several schools of thought have emerged on this all important concept. Many viewed the use of incinerators as a good option. Those who subscribe to the use of incinerators argue that the heat generated by incineration can be used to generate electric power. Also, incinerators reduce the solid mass of the original waste by $80-85 \%$ and the volume by $95-$ $96 \%$ depending on composition and degree of recovery of materials such as metals from the recycling [12]. This means that while incineration does not completely replace landfilling, it significantly reduces the necessary volume of disposal. Ash from modern incinerators can be made to reduce the leachability and toxicity of residue. Special landfills are generally no longer required for incineration of ash from solid waste streams, and existing landfills can see their life dramatically increased by combusting waste, reducing the need for municipalities to site and construct new landfills [13]. Furthermore, incineration of solid waste avoids the release of methane. Every ton of solid waste incinerated, prevents about one ton of Carbon dioxide equivalents from being released to the atmosphere [14].

\subsection{A. Bad Practice}

Another school of thought believed that incineration is a bad practice in both developed and developing countries. The dioxins and furan emissions into the atmosphere where found to cause cancer especially during start up and shut down, or where filter bypass is required [15]. Incinerators emit varying levels of heavy metals such as Vanadium, Nickel, Mercury, Lead and Cadmium, which can be toxic at very minute levels. Ash is a product from incinerators. It must be safely disposed of. This usually involves lands and the need for specialist toxic waste landfills elsewhere. If not done properly, it may cause concerns for local residents [16]. Many developing countries around the world today are advocating for a ban on the use of incineration technologies, particularly Japan, USA and Europe. The incinerator companies in these countries are declining popularity and sales are looking for new markets.

The incineration facilities built in some developing countries like Nigeria, Brazil and Mexico have not been used. When they were used, as in Indonesia, the cost was prohibitive. The waste composition is largely organic in developing countries with high moisture content, making incineration a poor option.

\subsection{Economic Viability}

Incinerators require a large capital investment with little 
economic return. The plants need constant supply of waste for maintaining optional combustion, which results in the creation of incinerator [17]. This effectively destroys incentives for local decision-makers to minimize waste. Incinerators need material with high calorific value, such as paper, cardboard and plastics to maintain combustion levels [18]. In fact, the only materials in mixed waste that exceed the average calorific value of standard power generating fuels (such as natural diesel) are waste oils, solvents and plastics, which produce air emission problems when burned [19]. In developing countries waste consists mainly of organic matter; for instance in Sierra Leone cities, organic content varied between $60-83 \%$ of the total waste (Table 1 ). Also, the garbage contains less paper and cardboard, plastic, metal and glass, which makes it economically less viable to operate in developing countries.

\section{Conclusion}

Recovery is a fundamental concept in a limited resource nation towards sustainable development. Many nations, the world over are now aware of that need. Therefore, a recovery centric approach to municipal solid waste management cannot be functional, without active citizen participation and proper implementation of regulations. Sample studies have shown that it is possible to achieve a recovery-eccentric approach by altering citizen behaviour. Based upon the results of this paper, it is very clear that composting after segregation is the best possible option to address solid waste disposal in developing countries. In many developing countries, there are no composting plants installed. Those countries that have installed composting technologies have failed due to lack of streamlined collection of waste by waste management authorities. Therefore, windrow composting, the least expensive, can be appropriate to the socioeconomic and climatic conditions in developing countries.

\section{References}

[1] M. Pacione: Urban geography: a global perspective (Taylor \& Francis US 2009).

[2] J. E. Hardoy et al Environmental Problems in an Urbanizing World: Finding Solutions in Solutions in Africa, Asia, and Latin America (Earthscan publication London 2001).

[3] UN-HABITAT, DFID: Sustainable Urbanization Achieving Agenda 21 London 2002.

[4] S. Cointreau: Declaration of principles for sustainable and integrated solid waste management. World Bank, Washington, DC 2001.
[5] S. Kruljac: Public-Private Partnerships in Developing Strategies for Brazil. Bulletin of Latin 236.

[6] S. Abul: 2010. Environmental and Health Impact of Solid Waste Disposal at Mangwaneni Dumpsite in Manzini, Swaziland. Joumal of Sustainable Development in Africa Vol. 12(2010) p. 64-78

[7] M. Aatamila et al: Odour annoyance and physical symptoms among residents living near waste treatment centres. Environmental research Vol. 1 I 1(2011), p. 164-170.

[8] R. V. Mangizvo and M. Wiseman: The Management, Practice and Environmental Health Implications of the Municipal Solid Waste Dump Site in Alice, South Africa. Online Journal of Social Sciences Research Vol. 1 (2012), p. 125-131

[9] I. O. Ogunrinola and E. O. Adepegba: Health and economic implications of waste dumpsites in cities: The case of Lagos, Nigeria. International Joumal of Economics and Finance Vol. 4(2012), p. 239.

[10] M. Medina: Globalization, development, and municipal solid waste management in third world cities. Tijuana, Mexico: El Colegio de la Forntera Norte (2002), p. 199.

[11] D. Sood: Solid Waste Management Study for Freetown, Sierra Leone. Component Design for the World Bank, Draft Report Project (2004).

[12] H. Kleis and S. Dalager: 100 years of waste incineration in Denmark. Babcock \& Wilcox Valund and RAMBOLL Vol. 7(2004).

[13] M. Firestone et al.: The US Environmental Protection Agency strategic plan for evaluating the toxicity of chemicals. Journal of Toxicology and Environmental Health, Part B Vol. 13(2010) p. 139-162.

[14] T. Fruegaard, T. H. Chritensen and T. Astrup: Energy recovery from waste incineration: Assessing the importance of district heating networks. Waste Management Vol. 30(2010), p. 12641272.

[15] R. E. Alcock et al: Dioxin-like PCBs in the environmental human exposure and the significance of sources. Chemosphere Vol. 37(1998), p. 1457-1472.

[16] O. van Steenis: Incinerators: Weapons of Mass Destruction. Summary of paper at the RIBA Conference $31^{\text {st }} \mathrm{Jan}-2^{\text {nd }} \mathrm{Feb}$, 2005.

[17] P. Connett and E. Connett: 1994. Municipal waste incineration: Wrong question, wrong answer. Ecologist Vol. 24(1994, p. 14-20.

[18] C. Lee and G. L. Huffman: 1996. Medical waste management/incineration. Journal of Hazardous Materials Vol. 48(1996), p. 1-30.

[19] H. J. Spooner: 2010. Wealth from Waste, Elimination of Waste a World Problem (Taylor \& Francis 2010). 